Ashraf Abdel Kader Ahmed MD, *

Masato Kumagai MD,

Tomoko Otake MD,

Yutaka Kurata MD,

Yoshikiyo Amaki MD

\section{Sevoflurane exposure time and the neuromus- cular blocking effect of vecuronium}

Purpose: To determine the effect of sevoflurane exposure time on the duration of vecuronium neuromuscular blockade.

Methods: In 40 adult patients anesthesia was induced with $1.5-2 \mathrm{mg} \mathrm{kg}^{-1}$ propofol and $3-5 \mu \mathrm{g} \cdot \mathrm{kg}^{-1}$ fentanyl and the trachea was intubated without the aid of muscle relaxant. Patients were randomized into four groups of 10. In group I, $0.05 \mathrm{mg} \cdot \mathrm{kg}^{-1}$ vecuronium was administered with $\mathrm{N}_{2} \mathrm{O}$ and anesthesia was maintained by propofol infusion and fentanyl. Vecuronium was administered with sevoflurane $2 \%$ in 30 patients, commencing at the same time (group 2) and at 30, and 60 min after sevoflurane (groups 3, 4). Adductor pollicis force of contraction to train-of-four ulnar nerve stimulation was recorded. Times from vecuronium injection to $95 \%$, maximal block, and recovery times to $25 \%$ recovery were recorded.

Results: There were no differences in times to $95 \%$ and maximal block in the four groups. Recovery times were longer in groups 3 and 4 than in groups 2 and I $(P<0.01)$. Times to $5 \%$ recovery were $15.0 \pm 3.7,17.8 \pm$ $4.8,28.2 \pm 9.9$, and $29.5 \pm 9.5$, and to $25 \%$ recovery were $22.3 \pm 5.2,27.2 \pm 6.4,42.3 \pm 16.3$, and 50.5 \pm 16.4 in groups $1,2,3$, and 4 respectively. No differences were found between group I and group 2 nor between group 3 and group 4 .

Conclusion: Sevoflurane produced time-dependent potentiation of vecuronium. After 30 min exposure, $25 \%$ recovery was prolonged by $89 \%$ and after 60 min by more than 100\% compared with the control group.

Objectif : Déterminer l'effet du temps d'exposition au sévoflurane sur la durée du blocage neuromusculaire avec du vécuronium.

Méthode : On a induit l'anesthésie avec 1,5-2 $\mathrm{mg} \cdot \mathrm{kg}^{-1}$ de propofol et 3-5 $\mu \mathrm{g} \cdot \mathrm{kg}^{-1}$ de fentanyl chez 40 patients adultes et on a procédé à l'intubation endotrachéale sans myorelaxant. Les patients ont été répartis en quatre groupes de 10. Dans le groupe I, on a administré $0,05 \mathrm{mg} \cdot \mathrm{kg}^{-1}$ de vécuronium avec $\mathrm{N}_{2} \mathrm{O}$ et on a maintenu l'anesthésie avec une perfusion de propofol et de fentanyl. Chez 30 patients, le vécuronium a été administré avec le sévoflurane $2 \%$, en même temps aux patients du groupe 2 , mais 30 et 60 min après le sévoflurane à ceux des groupes 3 et 4 . La force de contraction de l'adducteur du pouce à la stimulation en train-de-quatre du nerf cubital a été notée. Le temps nécessaire pour que le vécuronium injecté produise $95 \%$ du bloc, puis le bloc maximal, et le temps nécessaire pour atteindre une récupération de $25 \%$, ont été enregistrés.

Résultats : II n'y a pas eu de différence de temps intergroupe pour produire $95 \%$ du bloc, ni pour le bloc maximal. La récupération s'est prolongée dans les groupes 3 et 4 comparés aux groupes 2 et I $(P<0,01)$. Le temps nécessaire pour atteindre une récupération de $5 \%$ ont été de $15,0 \pm 3,7,17,8 \pm 4,8,28,2 \pm 9,9$, et de 29,5 $\pm 9,5$, et pour une récupération de $25 \%$ ont été de $22,3 \pm 5,2,27,2 \pm 6,4,42,3 \pm 16,3$, et de $50,5 \pm 16,4$ dans les groupes I, 2, 3, et 4 respectivement. Aucune différence n'a été rapportée entre les groupes I et 2 , ni entre les groupes 3 et 4 .

Conclusion : Le sévoflurane a produit une potentialisation du vécuronium dépendante du temps. Après $30 \mathrm{~min}$ d'exposition le temps nécessaire pour produire une récupération de $25 \%$ s'est accru de $89 \%$ et, après 60 min, de plus de $100 \%$, si on le compare au temps du groupe témoin.

From the Departments of Anesthesia, Jikei University School of Medicine, 3-25-8 Nishi-Shinbashi, Minato-Ku, Tokyo, Japan and Ain Shams University, ${ }^{*}$ Cairo, Egypt.

Address correspondence to: Ashraf Abdel Kader Ahmed MD, Phone/Fax: 81-3-3436-1974; E-mail: kader2a@hotmail.com

Accepted for publication February 24, 1999 


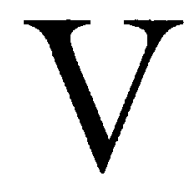

OLATILE anesthetics potentiate the neuromuscular blocking effect of non-depolarizing muscle relaxants, ${ }^{1-7}$ and this potentiation is dependent on the neuromuscular blocking agents, ${ }^{1,2}$ the specific inhalational anesthetic, ${ }^{3-5}$ and the concentration used. ${ }^{6,7}$ Recently, this potentiation has been suggested to be time depen$\operatorname{dent}^{8-11}$ but, in these studies, an infusion technique was used for relaxant administration, ${ }^{8-10}$ and inhalational anesthetics were initially administered at high concentration to achieve the desired end tidal anesthetic concentration quickly: none of which is common clinical practice. The maximum potentiating effect of inhalational anesthetics may not develop until the anesthetic has equilibrated with the muscle tissue, which may take one to two hours. ${ }^{12}$ Sevoflurane is a new inhalational anesthetic with low muscle-gas partition coefficient of $3.13,{ }^{13}$ suggesting that it may equilibrate rapidly with muscle tissue and that the maximum potentiating effect may be expected to be achieved quickly. This study was designed to demonstrate the effect of sevoflurane exposure time on the clinical duration of action of a single bolus dose of vecuronium.

\section{Methods}

The study protocol was approved by our department's ethical committee and informed consent was obtained from all patients. Forty adult patients ASA physical status 1-11 scheduled for elective surgical procedures requiring muscle relaxation were entered into the study. Patients with hepatic, renal or neuromuscular disease, or receiving drugs known to affect neuromuscular function were excluded. Patients with electrolyte imbalance or airway abnormality were also excluded. All patients were premedicated by $10 \mathrm{mg}$ diazepam po and $1 \mathrm{mg}$ atropine $i m$, administered one hour before operation. Anesthesia was induced with $1.5-2 \mathrm{mg} \cdot \mathrm{kg}^{-1}$ propofol with $3-5 \mu \mathrm{g} \cdot \mathrm{kg}^{-1}$ fentanyl and the trachea was intubated without the aid of muscle relaxant. Anesthesia was maintained with intermittent doses of propofol and fentanyl as clinically indicated. The ECG, blood pressure, and oxygen saturation were monitored. Esophageal or rectal temperature was monitored and maintained above $36 \mathrm{C}$ by covering any exposed part of the patient, using heating mattress, and adjustment of room temperature. Inspired and end tidal sevoflurane concentration and $\mathrm{P}_{\mathrm{ET}} \mathrm{CO}_{2}$ were continuously monitored by multigas analyzer (Capnomac, Ultima, Datex). Ventilation was controlled to maintain $\mathrm{P}_{\mathrm{ET}} \mathrm{CO}_{2}$ around $35 \mathrm{mmHg}$. Neuromuscular monitoring was done by measuring the adductor pollicis force of contraction in response to supramaximal TOF (train-of-four) stimulation of the ulnar nerve close to the wrist. The stimula- tion was delivered at $2 \mathrm{~Hz}$ frequency every $12 \mathrm{sec}$. The first twitch in the train was considered as control twitch height, and a preload of $200-250 \mathrm{~g}$ was applied to the thumb. The resulting current was amplified and then recorded on a polygraph (8M36 Omnilite, NEC Sanei). A stable base line was maintained for at least $10 \mathrm{~min}$ before administration of vecuronium or sevoflurane. Patients were then randomized into four groups, 10 patients each. In group 1 , anesthesia was maintained with a continuous infusion of propofol and a single bolus dose of $0.05 \mathrm{mg} \cdot \mathrm{kg}^{-1}$ vecuronium was administered together with nitrous oxide $50 \%$. In group 2 , patients received sevoflurane $2 \%$ inspired together with the same dose of vecuronium. In groups 3 and 4, patients received the same inspired concentration of sevoflurane as in group 2 but for 30 and $60 \mathrm{~min}$, before administration of the same dose of vecuronium. Times to $95 \%$ block and onset time (time from vecuronium administration to maximum twitch depression), and recovery times up to $\mathrm{T}_{25}$ (25\% recovery of control twitch height, clinical duration of action) were recorded. All values are presented as mean $\pm S D$. Statistical analysis of the data was performed using one-way ANOVA, followed by Bonferroni correction. A $P$ value $<0.05$ was considered significant.

\section{Results}

A difference was found between group 4 and group 1 with respect to age and weight but no differences were found between the other study groups (Table I). No differences were found regarding times to $95 \%$ and maximum block (Table II). Complete neuromuscular block was achieved in all patients. Times to $25 \%$ recov-

TABLE I Patients characteristics for the study groups

\begin{tabular}{lllll}
\hline $\begin{array}{l}\text { Patients } \\
\text { characters }\end{array}$ & Group 1 & Group 2 & Group 3 & Group 4 \\
\hline Age $(\mathrm{yr})$ & $44.5 \pm 8.5$ & $45.4 \pm 11.3$ & $\mathbf{5 0 . 5} \pm 11.6$ & $\mathbf{5 5 . 5} \pm 8.7^{*}$ \\
Gender $\mathrm{m}: \mathrm{f}$ & $3: 7$ & $2: 8$ & $4: 6$ & $6: 4$ \\
Weight $(\mathrm{kg})$ & $49.2 \pm 8.8$ & $\mathbf{5 5 . 5} \pm 9.6$ & $\mathbf{5 9 . 2} \pm 11.6$ & $\mathbf{5 9 . 7} \pm 7.1^{*}$ \\
\hline
\end{tabular}

Mean \pm SD. $P^{*}<0.05$ compared with group 1 .

TABLE II Onset and recovery data

\begin{tabular}{lllll}
\hline Times & group 1 & group 2 & group 3 & group 4 \\
\hline to $95 \%$ block & $2.7 \pm 0.5$ & $2.5 \pm 0.6$ & $2.4 \pm 0.7$ & $2.9 \pm 0.9$ \\
to max block & $3.5 \pm 0.7$ & $3.0 \pm 0.7$ & $2.9 \pm 0.6$ & $3.5 \pm 0.6$ \\
to $5 \%$ recovery & $15.0 \pm 3.7$ & $17.8 \pm 4.8$ & $28.2 \pm 9.9^{*} \dagger$ & $29.5 \pm 9.5^{\star} \dagger$ \\
to $25 \%$ & & & & \\
recovery & $22.3 \pm 5.2$ & $27.2 \pm 6.4$ & $42.3 \pm 16.3^{*} \dagger 50.5 \pm 16.4^{*} \dagger$ \\
\hline
\end{tabular}

Mean $\pm S D$

$\star P<0.05$ compared with group $1, \dagger$ compared with group 2 . 
ery were prolonged in the 30 and $60 \mathrm{~min}$ exposure groups, group 3 and 4 , respectively, compared with group 1 and group 2 (Table II). In group $3, P$ values were .0009 and .0036 , and in group 4 were $<.0001$ and .0002 , respectively, compared with group 1 and 2 . No differences were found between groups 1 and 2 or between groups 3 and 4 . Although clinical duration (time to $25 \%$ recovery) was numerically longer in group 4 than in group 3 , the difference was not statistically significant.

\section{Discussion}

The results of this study demonstrate that exposure to $30 \mathrm{~min}$ and $60 \mathrm{~min}$ sevoflurane anesthesia is sufficient to prolong the duration of vecuronium neuromuscular blocking effect. When sevoflurane was administered together with vecuronium, group 2 , the duration of action was not prolonged compared with that in the propofol-fentanyl group, group 1 , suggesting that the muscle concentration may not reach a sufficient level to produce a potentiating effect. However, $30 \mathrm{~min}$ of sevoflurane exposure (group 3) produced prolongation of the clinical duration of action by $89 \%$ and after 60 min exposure (group 4) the duration was more than double that in group 1. Clinical duration of action was chosen as it is believed to provide satisfactory relaxation for the majority of surgical procedures. ${ }^{14}$

Few studies have been done demonstrating the time course potentiation effect of inhalational anesthetics. Jalkmanen and Meretoja, found that $10 \mathrm{~min}$ exposure to isoflurane was insufficient to affect mivacurium spontaneous recovery, but $\mathbf{3 0} \mathrm{min}$ exposure prolonged recovery by $55-58 \% .{ }^{11}$ Meretoja et al., found that potentiation of mivacurium by halothane and isoflurane was strongly time dependent and took at least $30 \mathrm{~min}$ before maximum potentiation was established. ${ }^{10}$ The infusion rate of mivacurium in subjects anesthetized with halothane and isoflurane was reduced maximally to $32 \%$ and $70 \%$ after $90 \mathrm{~min}$ of anesthetic inhalation. Withington $e t$ al. evaluated the time course of potentiation of atracurium by enflurane. ${ }^{9}$ They found a timedependent reduction in the plasma concentration of atracurium needed to maintain $90 \%$ neuromuscular block. Exposure to $1 \mathrm{MAC}$ enflurane was not associated with decreases in atracurium plasma concentration up to $30 \mathrm{~min}$. However, at $\mathbf{4 5} \mathrm{min}$, atracurium plasma concentration was decreased by $33 \%$ and at two hours by $52 \%$. They concluded that, the potentiating effect of atracurium by enflurane was negligible during procedures of less than $45 \mathrm{~min}$. Stanski et al. found that when the plasma concentration of $d$-tubocurarine was kept constant, neuromuscular blockade was increased slowly by enflurane with time, at approximately $9 \%$ per hour. ${ }^{9}$
Muscle tissue equilibrates with the partial pressure of the volatile anesthetic in arterial blood within onefour hours, ${ }^{12}$ and, as inhalational anesthetics differ in their muscle solubility, ${ }^{13}$ it is expected that each inhalational anesthetic has its own time course potentiation effect. In this study, the maximum time dependent potentiating effect of sevoflurane was reached at $30 \mathrm{~min}$, and no difference was found at $60 \mathrm{~min}$ exposure time. While using enflurane, a more soluble anesthetic, ${ }^{12}$ the potentiating effects of atracurium appear to increase even after a two hour exposure. ${ }^{9}$ Up to 90 min exposure to halothane and isoflurane was associated with decrease in mivacurium infusion rate. ${ }^{10}$

Sevoflurane is a new inhalational anesthetic with low muscle-gas partition coefficient of $3.13,{ }^{13}$ its neuromuscular effect has not been characterized. However, Morita et al. ${ }^{15}$ and Kurahashi and Maruta ${ }^{16}$ compared the neuromuscular effect of sevoflurane with that of isoflurane and found no difference between them as regard their neuromuscular effects. Unfortunately, exposure time was not fixed in both studies, ranging between $8-27 \mathrm{~min}^{16}$ and $>40 \mathrm{~min}^{15}$ To our knowledge, no study has been published to demonstrate the time dependent potentiating effect of sevoflurane. However, its low muscle-gas partition coefficient suggests that equilibration between muscle and blood may not take as long as with halothane, enflurane, and isoflurane and this may explain why 60 min exposure did not produce any greater difference than with $\mathbf{3 0}$ min exposure.

Unexpectedly, onset time did not differ among the four groups. Jalkanen and Meretoja found that $30 \mathrm{~min}$ isoflurane exposure produced shorter onset time than in the control group. ${ }^{11}$ We do not have an exact explanation of this difference but isoflurane, in addition to its neuromuscular effect, produces marked vasodilatation of muscle blood vessels, ${ }^{17}$ which may result in delivery of relatively more relaxant to the motor end plate producing a more rapid effect.

Administration of sevoflurane together with vecuronium, a common clinical practice, did not prolong the clinical duration of vecuronium. Thus, there is no need to reduce the initial bolus dose even with the use of sevoflurane. However, $30 \mathrm{~min}$ sevoflurane exposure is associated with increased neuromuscular block and this should be taken into consideration in operations lasting more than $30 \mathrm{~min}$.

\section{References}

1 Swen J, Rashkovsky OM, Ket JM, Koot HWJ, Hermans J, Agoston S. Interaction between nondepolarizing neuromuscular blocking agents and inhalational anesthetics. Anesth Analg 1989; 69: 752-5. 
2 Miller RD, Way WL, Dolan WM, Stevens WC, Eger EI II. Comparative neuromuscular effects of pancuronium, gallamine, and succinylcholine during forane and halothane anesthesia in man. Anesthesiology 1971; 35: 509-14.

3 Cannon JE, Fabey MR, Castagnoli KP, et al. Continuous infusion of vecuronium. The effect of anesthetic agents. Anesthesiology 1987; 67: 503-6.

4 Walts LF, Dillon JB. The influence of the anesthetic agent on the action of curare in man. Anesth Analg 1970; 49: 17-20.

5 Rupp SM, Miller RD, Gencarelli PJ. Vecuroniuminduced neuromuscular blockade during enflurane, isoflurane, and halothane anesthesia in humans. Anesthesiology 1984; 60: 102-5.

6 Aziz L, Obta $Y$, Nakatsuka H, Takata F, Morita K, Hirakawa $M$. Effect of isoflurane and sevoflurane on the potencies of muscle relaxants in rat in vipo. Anesth Analg 1995; 80: S26.

7 Gencarelli PJ, Miller RD, Eger EI 11, Newfield P. Decreasing enflurane concentrations and $d$-tubucurarine neuromuscular blockade. Anesthesiology 1982; 56: $192-4$.

8 Stanski DR, Ham J, Miller RD, Sheiner LB. Time-dependent increase in sensitivity to $d$-tubocurarine during enflurane anesthesia in man. Anesthesiology 1980; 52: 483-7.

9 Withington $D E$, Donati $F$, Bepan $D R$, Varin $F$. Potentiation of atracurium neuromuscular blockade by enflurane: time-course of effect. Anesth Analg 1991; 72: 469-73.

10 Meretoja OA, Wirtavuori $K$, Taivainen T, Olkkola KT. Time course of potentiation of mivacurium by halothane and isoflurane in children. $\mathrm{Br} \mathrm{J}$ Anaesth 1996; 76: 235-8.

11 Jalkanen $L$, Meretoja $O A$. The influence of the duration of isoflurane anaesthesia on neuromuscular effects of mivacurium. Acta Anaesthesiol Scand 1997; 41: 248-51.

12 Eger EI II. Anesthetic Uptake and Action. Baltimore: Williams and Wilkins Company, 1974.

13 rasuda N, Targ AG, Eger EI II. Solubility of I-653, sevoflurane, isoflurane, and halothane in human tissues. Anesth Analg 1989; 69: 370-3.

14 Ali HH, Savarese JJ. Monitoring of neuromuscular function. Anesthesiology 1976; 45: 216-49.

15 Morita T, Tsukagoshi H, Sugaya T, Yoshikawa D, Fujita $T$. The effects of sevoflurane are similar to those of isoflurane on the neuromuscular block produced by vecuronium. Br J Anaesth 1994; 72: 465-7.

16 Kurabashi $K$, Maruta $H$. The effect of sevoflurane and isoflurane on the neuromuscular block produced by vecuronium continuous infusion. Anesth Analg 1996; 82: 942-7.

17 Eger EI II. Isoflurane: a review. Anesthesiology 1981; 55: 559-76. 